\title{
Ultra-Deepwater Riserless Mud Circulation with Dual Gradient Drilling
}

by Greg Myers

doi:10.2204/iodp.sd.6.07.2008

\section{Introduction}

Drilling deep holes in very deep water presents the offshore drilling community with major wellbore stability challenges that are typically mitigated through the circulation of dense drilling mud to prevent hole collapse and to remove drilling debris ("cuttings"). This is normally accomplished through the application of a riser system (Fig. 1); however, riser lengths are presently limited to use in water depths of around $3047 \mathrm{~m}$. In the scientific ocean drilling realm, we have been very successful in drilling relatively shallow holes $(<1500 \mathrm{~m})$ in water depths greater than $3657 \mathrm{~m}$, a range we call "hyper-deep". Drilling in these extreme water depths requires the use of the "riserless" drilling technique (Fig. 1A) which is not constrained by the length limitations of a riser system ("riser").

The new riser-capable drilling vessel Chikyu has enabled the Integrated Ocean Drilling Program (IODP) to drill deep holes in water depths up to $2500 \mathrm{~m}$. Scientific objectives in greater water depths with borehole penetrations deeper than

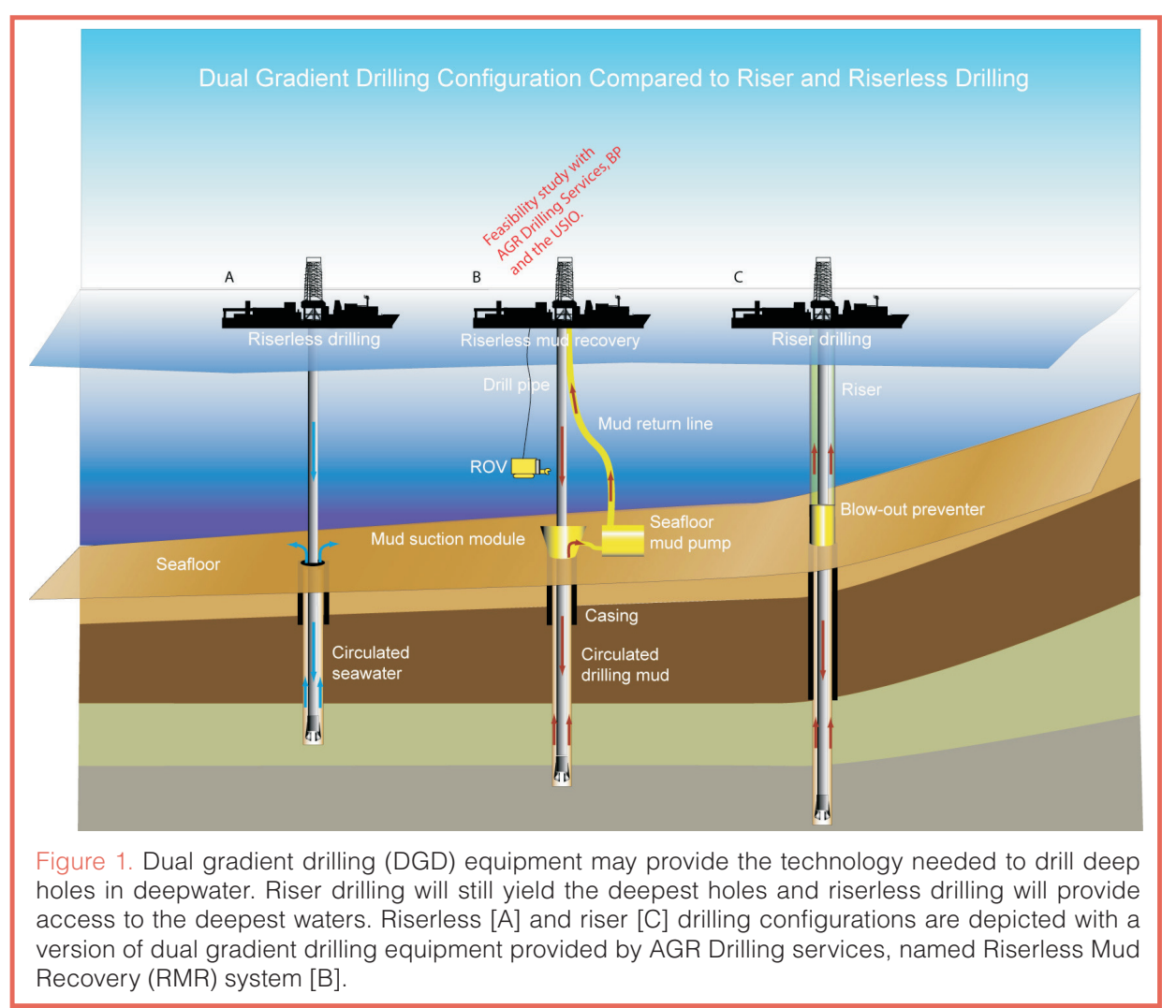

$2000 \mathrm{~m}$ still remain a major challenge, because IODP does not have effective options for drilling in these environments. A technological solution to improve the drilling of deep holes in ultra-deep water with riserless drilling equipment may now be emerging through a joint effort between IODP-Management International (IODP-MI) and the energy industry. The technology, known as Riserless Mud Recovery (RMR), has been developed and commercialized by the Norwegian firm, AGR Drilling Services (http://www.agr. com/). The RMR system allows for the drilling of the upper section of a borehole using the dual gradient drilling technique (Fig. 1B). The AGR system is presently operating in water depths up to $457 \mathrm{~m}$. This article describes this emerging drilling technology and outlines joint efforts by IODP-MI and the energy industry to modify the system and deploy it in water depths up to $3657 \mathrm{~m}$.

\section{Summation of Offshore Drilling Problem - Well Control and Costs}

Whether a drill site is located in terrestrial or marine environments, several problems are common to rotary drilling operations. Drilling cuttings must be removed from the borehole, drilling fluid density must be managed to keep the borehole open without fracturing the formation, circulation must be maintained even when drilling fluid is lost to the formation, and pressure must be contained if over-pressured strata or gas are encountered (Weddle and Schubert, 2000). These problems are exacerbated for offshore wells due to hydrostatic pressure constraints, especially in the upper section of the borehole where the sedimentary overburden is reduced and/or increased pore pressures may be encountered (Fig. 2).

The result of this dynamic is a narrowing of the drilling "window" between the formation pore pressure and formation fracture pressure (Smith et al., 1999). As water depth increases, the "window" 
between the pore pressure and fracture pressure becomes even narrower as a result of the increasing influence of the weight of the fluid column.

Riserless drilling primarily uses seawater, rather than drilling mud, to manage the borehole because drilling mud cannot be recirculated. Seawater has a significantly lower density than drilling mud, thus the boreholes are more likely to collapse with increasing hole depth as the pore pressure exceeds the hydrostatic pressure exerted by the seawater. For deeper drilling, drilling mud with regulated density must be continuously circulated in order to keep the borehole from collapsing and to remove cuttings from the borehole. The widely accepted standard equipment to establish continuous circulation is a marine drilling riser, which provides a conduit for returning the mud and cuttings to the drill rig. Current riser depth capabilities, however, only extend to just over $3047 \mathrm{~m}$ and are extremely expensive. Scientific ocean drilling and the energy industry have ultra-deepwater targets of interest beyond the reach of current risers. Research is underway to design risers of even greater depth potential using a combination of metallic and composite materials. However, the stresses due to vibration of these long riser strings and the well control problems associated with hydrostatic pressure of the mud pose significant operational problems. The use of alternate techniques, such as riserless mud recovery and dual gradient drilling, could therefore provide an attractive option for both IODP and industry to drill deep holes in deep water settings where current capabilities are either insufficient or not economic.

\section{Dual Gradient Drilling Application for IODP}

RMR provides a dual gradient drilling setup of the well, while capturing the drilling fluid and returning it to the drillship (Fig. 3). The term "dual gradient" implies two hydrostatic gradients: 1) the seawater gradient that begins at the sea surface, and 2) the drilling mud gradient that begins at the seafloor. Conventional drilling has only one pressure gradient for both seawater and mud that originates at the sea surface (Schubert, et al., 1999). Because dual gradient drilling has much less hydrostatic "head" associated with the drilling mud in the borehole, drilling fluids can be properly weighted, allowing drilling to be more easily

contained within the "window" between the formation pore pressure (Fig. 3, red line) and the formation fracture pressure (blue line), thereby avoiding wellbore instability.

Riser drilling and dual gradient drilling provide different options for controlling borehole conditions while drilling. The primary difference is the point where the hydrostatic head of the drilling mud begins accumulating. Another way of visualizing dual gradient drilling is to imagine the drilling equipment positioned on the seafloor. In this scenario, the weight of the fluid column from the sea surface down to the seafloor is eliminated, thereby providing a larger drilling "window" between the formation pore pressure and formation fracture pressures, resulting in increased well bore pressure management.

In addition to well control, the RMR system also helps reduce the costs associated with deepwater drilling. First, the system eliminates the "pump and dump" drilling strategy, where mud that is sometimes utilized for well control in riserless drilling is directly discharged to the 
seafloor. Collecting and reusing drilling mud significantly reduces the amount of mud required to install an offshore well. Second, as the number of casing strings can be reduced, the upfront costs for this material can be significantly reduced. Thus, the RMR system offers a complementary solution to the capabilities of the Chikyu and the standard riserless capabilities of the JOIDES Resolution. Chikyu provides much deeper borehole penetration with blow-out prevention capabilities, but it has a limited water depth range. The current JOIDES Resolution provides hyper-deepwater capabilities but with limited borehole penetration. A drilling platform successfully equipped with RMR and dual gradient capabilities would fill in this technology gap in a cost-effective manner, allowing pursuit of deep drilling targets in water depths up to

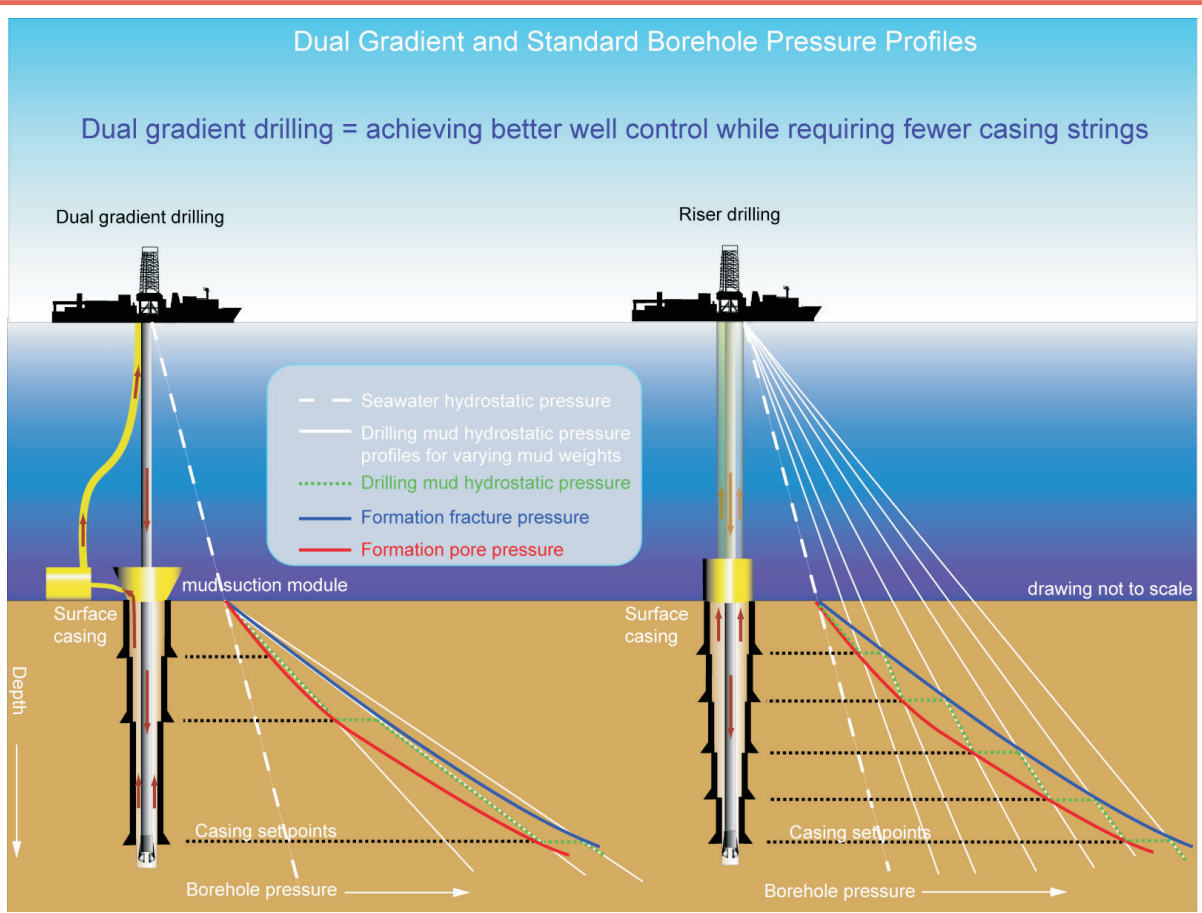

Figure 3. The dual gradient drilling approach establishes the drilling mud hydrostatic gradient at the seafloor which allows for the use of heavier drilling muds with an advantageous pressure increase with depth. The use of optimized drilling mud provides better well control and fewer casing points by keeping the drilling fluid within the drilling "window" for more depths within the borehole. $3657 \mathrm{~m}$

AGR Drilling Services has been providing RMR dual gradient drilling equipment to the energy industry for a number of years. The system has been successfully utilized in gas fields in Sakhalin (Brown et al., 2007) and the Caspian Sea. The equipment is mobilized and installed on the drill rig in modular sea-freight containers. Returning the drilling mud back to the drill rig for conditioning and recirculation requires seafloor mud suction equipment (Figs. 4 and 5), seafloor mud pumps, and a mud return line extending from the seafloor equipment back to the drill rig. In shallower water depths below $1524 \mathrm{~m}$, this line can be a flexible, large-diameter hose. Beyond $1524 \mathrm{~m}$, the mud return line will be fashioned from steel pipe, such as a drill pipe. The mud return line is deployed down to the seafloor and then secured as the pipe exits the rig's moon pool. A remotely operated vehicle (ROV) is utilized to provide visual inspection of the seafloor equipment setup. Following the equipment setup, the drill string is run to the seafloor, and the hole is spudded. The ROV system is deployed continuously to monitor the mud recovery system during drilling.

To investigate the feasibility of utilizing the RMR system on the JOIDES Resolution to $3657 \mathrm{~m}$, a small team was formed by IODP-MI with members from the IODP United States Implementing Organization (USIO), AGR Drilling Services, and British Petroleum (BP). This team submitted afeasibility and planning proposal to DeepStar, an industry technology development consortium consisting of eight energy companies focused on advancing the technolo- gies to meet deepwater and ultra-deepwater business needs. DeepStar provides a forum to execute deepwater technology development projects and leverage the financial and technical resources of the deepwater industry (www.deepstar. org).

The study, planned for completion by the end of 2008, will investigate the system requirements for several different well configurations and water depths ranging from $1523 \mathrm{~m}$ to $3657 \mathrm{~m}$, depths of interest to both the energy industry and the scientific community. This study includes determining the feasibility studies of modifying the deepwater AGR

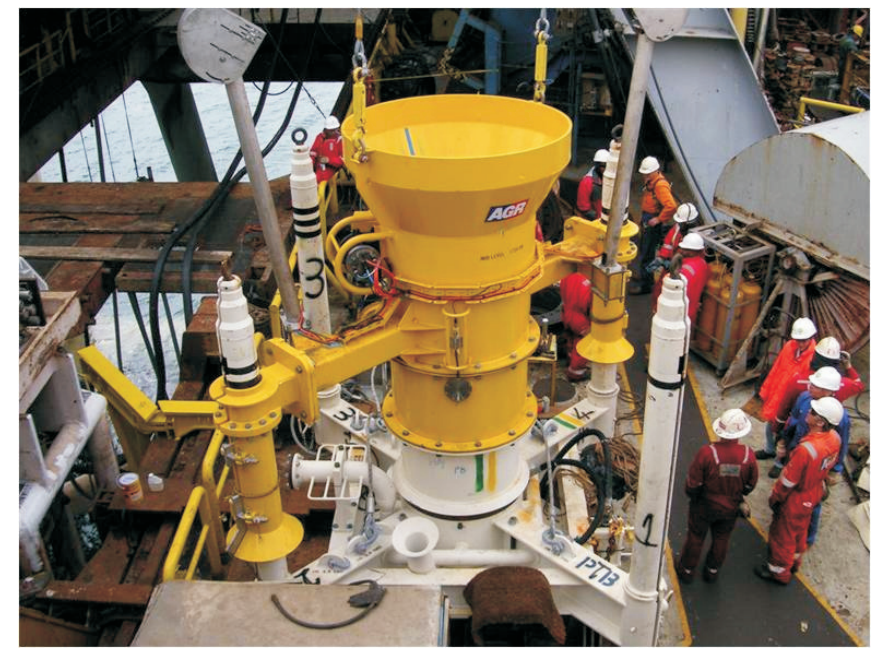

Figure 4. The AGR riserless mud recovery subsea equipment consists of a mud suction module (see above) and seafloor mud pumps. The mud is collected in the mud suction module and returned to the drillship via the seafloor mud pumps (image: courtesy of John Thorogood). 


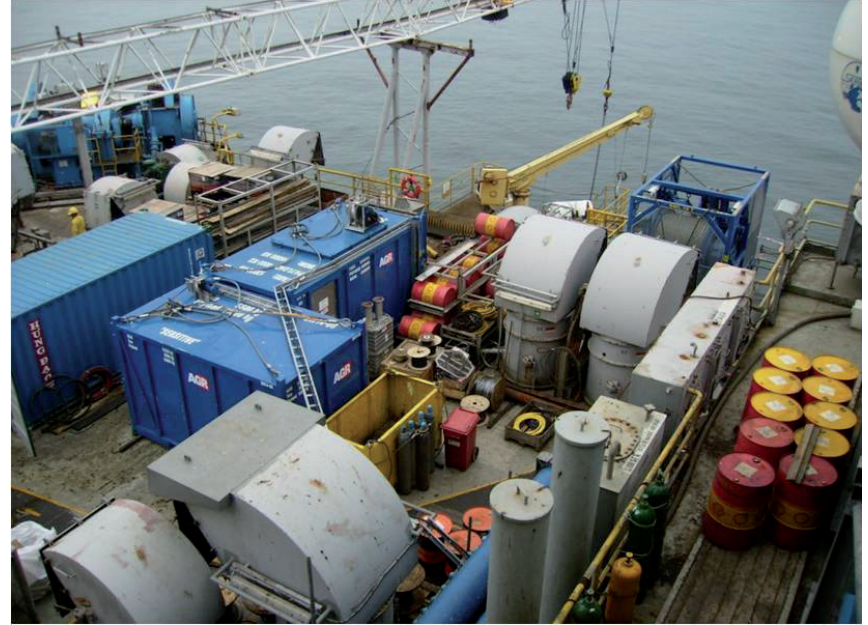

Figure 5. The AGR riserless mud recovery system deployed on an oil and gas exploration vessel.

system to operate in up to $3657 \mathrm{~m}$ of water and a feasibility study to determine the suitability of the JOIDES Resolution to deploy the AGR RMR system. Should the feasibility study show that the RMR system can be deployed from the JOIDES Resolution, IODP-MI will work with the USIO, AGR, and BP to secure funds for a Gulf of Mexico deployment within two years to test the system capabilities in actual field operations.

\section{Conclusions and Applications}

If RMR and dual gradient drilling prove feasible for use on the JOIDES Resolution, IODP will be in a much improved position to address drilling problems (Larsen and Kushiro, 1997) that consistently plagued the successful completion of highly ranked programs such as achieving deep crustal and even upper mantle objectives. And, it could open new areas of study in drilling deeper targets in over-pressured regions by providing a continuous supply of weighted mud needed to suppress shallow water flows (Myers et al., 2007). The modified AGR Drilling Services system could be leased as needed and deployed from the JOIDES Resolution, Chikyu, or another suitable platform as required to meet the scientific objectives of a given project.

\section{Acknowledgements}

The concepts and ideas presented in this article represent the amalgamation of previous work and informal discussions with many engineers from industry and scientific drilling circles. I wish to acknowledge all who have helped developed this concept on any level, in particular, Pierre Beynet and Warren Winters at BP, Tom Janecek of IODP-MI and Tom Williams helped turn these thoughts into an engineering initiative. Special thanks to Chris Haver and Jim Chitwood of the DeepStar consortium for hearing our proposal and seeing the value in symbiotic industry and scientific engineering efforts.

\section{References}

Brown, J.D., Urvant, V.V., Thorogood, J.L., and Rolland, N.L., 2007. Deployment of a riserless mud recovery system offshore Sakhalin Island. Presentation 105212, SPE/IADC Drilling Conference and Exhibition, 20-22 February 2007, Amsterdam, The Netherlands.

Larsen, H.C., and Kushiro, I., 1997. Report of the Conference on Cooperative Ocean Riser Drilling (CONCORD). 22-24 July 1997, Tokyo, Japan. http://www.odplegacy.org/PDF/ Admin/Long_Range/CONCORD.pdf.

Myers, G., Winker, C., Dugan, B., Moore, C., M., Sawyer, D., Flemings, P., and Iturrino, G., 2007. Ursa Basin explorers shine new light on shallow water flow. Offshore Engineer, September 2007, pp. 88-93.

Schubert, J.J., Seland, S., Johansen, T.J., and Juvkam-Wold, H.C., 1999. Greater kick tolerance and fewer casing strings make dual gradient drilling a winner. IADC Well Control Conference of the Americas, 25-26 August 1999, Houston, Texas.

Smith, K.L., Gault, A.D., Witt, D.E., Peterman, C., Tangedahl, M., Weddle, C.E., Juvkam-Wold, H.C., and Schubert, J.J., 1999. Subsea mudlift drilling joint industry project achieving dual gradient drilling technology. World Oil, Deepwater Technology (supplement), August 1999. http://www.worldoil. com/Magazine/MAGAZINE_DETAIL.asp?ART_ID $=3539 \&$ MONTH_YEAR=Aug -1999 .

Weddle, C.E., and Schubert, J.J., 2000. Factors to consider in dual gradient well control. IADC Well Control Conference and Exhibition, 6-7 December 2000, Houston, Texas.

\section{Author}

Greg Myers, IODP-MI Engineering and Operations Manager, IODP-MI Headquarters, 815 Connecticut Avenue, NW, Suite 210, Washington, DC 20006 U.S.A., e-mail: gmyers@iodp.org.

\section{Related Web Links}

http://www.agr.com/

http://www.deepstar.org

\section{Photo Credits}

Figs. 4 and 5: courtesy of John Thorogood (Drilling Global Consultant LLP) 